Check for updates

Cite this: RSC Adv., 2020, 10, 21382

Received 14th April 2020

Accepted 28th May 2020

DOI: $10.1039 /$ dOra03335a

rsc.li/rsc-advances

\title{
The Baeyer-Villiger rearrangement with metal triflates: new developments toward mechanism $\uparrow$
}

\author{
Piotr Latos, (D) Agnieszka Siewniak, (D) Magdalena Sitko and Anna Chrobok (D) * \\ Based on MS analysis, the mechanism of the Baeyer-Villiger oxidation of cyclic ketones with hydrogen \\ peroxide using metal triflates $\left(\mathrm{Ga}(\mathrm{OTf})_{3}\right.$ and $\left.\mathrm{Er}(\mathrm{OTf})_{3}\right)$ as catalysts was proposed. In the case of \\ cyclohexanone as a substrate, dimeric, trimeric and tetrameric peroxide structures were detected.
}

The Baeyer-Villiger oxidation (BV) of cyclic ketones is a convenient method of lactone preparation. Lactones are specialty chemicals which are used, among others, in the pharmaceutical, flavour and fragrances, and agrochemical industries. ${ }^{1}$ Typical oxidants in the $\mathrm{BV}$ reaction are highly reactive organic peracids. However, due to their numerous disadvantages, such as sensitivity to shock and temperature, generation of corrosive waste, and hazardous storage and handling, attention is turned to more environmentally friendly hydrogen peroxide. ${ }^{2} \mathrm{H}_{2} \mathrm{O}_{2}$ is safer than peracids, in particular in concentrations lower than $70 \%$. The use of $\mathrm{H}_{2} \mathrm{O}_{2}$ in oxidation reaction results in the formation of water as a by-product. ${ }^{2}$ Nevertheless, hydrogen peroxide is kinetically inert and it is necessary to activate it. ${ }^{1-3}$ One of the types of catalysts used for hydrogen peroxide activation are Lewis acids ${ }^{4}$ which are characterized by high activity and selectivity, however, they suffer from poor stability in an aqueous environment. Tin-containing zeolites are one of the most promising Lewis acidic catalysts for the BV reaction. Their advantages include both their high activity and stability during recycling. ${ }^{5}$

Another interesting proposition to answer the issue concerning hydrolytic stability of Lewis acidic catalysts for BV oxidation is the use of metal trifluoromethanesulfonates (triflates). Some of them exhibit both relatively high hydrolytic stability and Lewis acidity. ${ }^{6,7}$ Berkessel $e t$ al. demonstrated that rare earth triflates, especially $\mathrm{Sc}(\mathrm{OTf})_{3}$, were extremely active in BV oxidation as catalysts using hydrogen peroxide as an oxidant. However, these studies were presented only for the oxidation of very reactive cyclobutanones. ${ }^{8}$

In our earlier work, silica-bound gallium(III) triflate was used for the oxidation of 2-adamantanone yielded unexpected $95 \%$ of lactone with $99 \%$ selectivity. ${ }^{9}$ Encouraged by this result a number of metal triflates, with tin(II) triflate as the most active,

Department of Chemical Organic Technology and Petrochemistry, Silesian University of Technology, Krzywoustego 4, 44-100 Gliwice, Poland. E-mail: Anna.Chrobok@ polsl.pl

$\uparrow$ Electronic supplementary information (ESI) available: MS spectra, experimental procedures. See DOI: 10.1039/d0ra03335a were proved to be active catalysts in Baeyer-Villiger oxidation of 2-adamantanone, giving full conversion of ketone after short reaction time (20 minutes using $0.1: 0.2: 2.0$ molar ratio of $\mathrm{Sn}(\mathrm{OTf})_{2}$ : ketone : $\left.30 \mathrm{wt} \% \mathrm{H}_{2} \mathrm{O}_{2}\right) .^{10}$

Although the BV oxidation was discovered in 1899 , attempts to establish the mechanism took the next fifty years. ${ }^{1} \mathrm{~A}$ generally accepted mechanism of the BV oxidation of carbonyl compounds with peracid assumes that in the first stage an attack of peracidic nucleophilic oxygen on the carbonyl carbon of the ketone occurs leading to a formation of tetraedric intermediate product, called Criegee adduct or intermediate. The second stage involves an 1,2-anionotropic rearrangement. This mechanism was confirmed by von E. Doering by a labeling experiment with benzophenone- $\mathrm{O}^{18}{ }^{11}$ In case of using peracids as oxidants the presence of catalyst is optional. ${ }^{2}$ When using hydrogen peroxide as the oxidant the addition of catalyst is required. Depending on the catalyst used various BV oxidation pathways are proposed. Catalysts can activate the ketone or oxidant, or both of them, and usually one of the activation methods dominates (Fig. 1). ${ }^{2}$

Metal triflates are generally considered as Lewis acids, however some of them can partially hydrolyze to triflic acid under the influence of water. Hence, they may participate in the

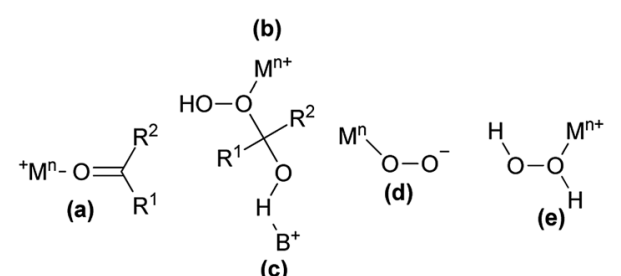

Fig. 1 Types of catalytic activation in the BV oxidation with hydrogen peroxide: (a) electrophilic activation of a ketone by the Lewis acid; (b) electrophilic activation of the Criegee adduct by the Lewis acid; (c) nucleophilic activation of the Criegee adduct by the Brønsted acid; (d) nucleophilic activation of hydrogen peroxide by the Lewis acid; (e) electrophilic activation of hydrogen peroxide by the Lewis acid. ${ }^{2} \mathrm{M}-$ Lewis acid, B - Brønsted acid. 


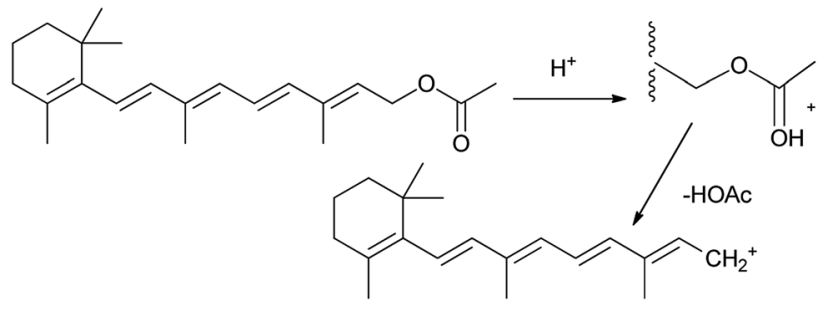

Fig. 2 Retinol carbocation formation..$^{12}$

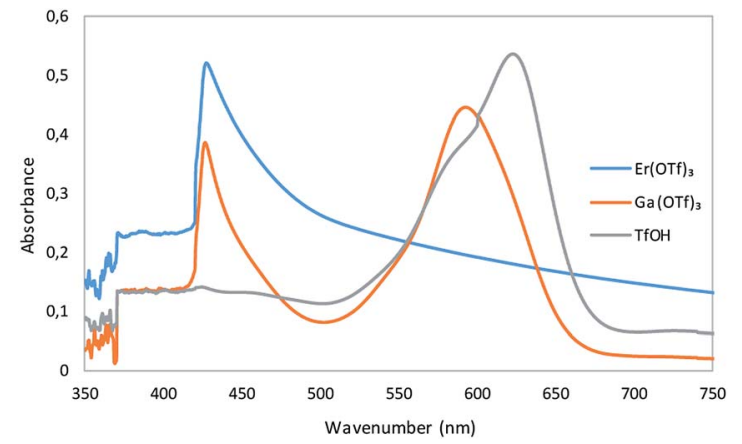

Fig. 3 UV-Vis spectroscopy of reaction mixtures consisting of metal triflates or triflic acid with retinyl acetate.

activation of the ketone, the Criegee intermediate or hydrogen peroxide, both by Lewis or Brønsted sites.

Herein, we decided to take a deeper look at the BV oxidation mechanism with hydrogen peroxide using selected metal triflates. The studies shed light for the role of metal triflates in the nonclassical approach of lactones formation concerning the highenergy compounds such as peroxides as intermediate compounds.

In the preliminary studies, two model metal triflates which significantly vary in hydrolytic stability: gallium(III) triflate and erbium(III) triflate were used to compare their stability in the presence of water. Test based on the reaction with retinyl acetate was conducted (Fig. 2). In this test, the presence of Brønsted acid in the test sample is confirmed by the formation of retinyl cation (blue color) from retinyl acetate (yellow) and detected by UV-Vis spectroscopy. ${ }^{12}$ Brønsted acid (triflic acid) in the studied samples of metal triflate may be formed by slow hydrolysis in the presence of traces of water. Therefore, triflic acid was used as a benchmark for these studies.

In order to limit the water content in UV-Vis tests, anhydrous nitrobenzene was used as a solvent. Results indicates (Fig. 3) that triflate with rare earth metal $\operatorname{Er}(\mathrm{OTf})_{3}$ was characterized by high hydrolytic stability and the presence of retinol carbocation was not observed while $\mathrm{Ga}(\mathrm{OTf})_{3}$ underwent partial hydrolysis as only part of the retinol acetate was converted to carbocation during tests. Due to the high reactivity of triflic acid, its amount used for the analysis was three times lower than that of metal triflates, which were used in the same molar amount.

In the case of triflic acid, all retinol acetate was transformed into retinol carbocation. The obtained results confirmed that $\operatorname{Er}(\mathrm{OTf})_{3}$ is hydrolytically stable Lewis acid comparing to $\mathrm{Ga}(\mathrm{OTf})_{3}$ which can undergo hydrolysis.
Table 1 Yields of lactones in the BV oxidation with hydrogen peroxide in the presence of metal triflates ${ }^{a}$

\begin{tabular}{llll}
\hline Ketone & Metal triflate & $\begin{array}{l}\text { Ketone } \\
\text { conversion }(\%)\end{array}$ & $\begin{array}{l}\text { Selectivity } \\
(\%)\end{array}$ \\
\hline $\begin{array}{l}\text { 2-Methylcyclohexanone } \\
\text { 2-Methylcyclohexanone }\end{array}$ & $\mathrm{Ga}(\mathrm{OTf})_{3}$ & 100 & 99 \\
Cyclobutanone & $\mathrm{Er}(\mathrm{OTf})_{3}$ & 97 & 94 \\
Cyclobutanone & $\mathrm{Ga}(\mathrm{OTf})_{3}$ & 100 & 100 \\
2-Adamantanone & $\mathrm{Er}(\mathrm{OTf})_{3}$ & 98 & 100 \\
2-Adamantanone & $\mathrm{Ga}(\mathrm{OTf})_{3}$ & 97 & 99 \\
Norcamphor & $\mathrm{Er}(\mathrm{OTf})_{3}$ & 94 & 80 \\
Norcamphor & $\mathrm{Ga}(\mathrm{OTf})_{3}$ & 98 & 99 \\
Cyclohexanone & $\mathrm{Er}(\mathrm{OTf})_{3}$ & 96 & 84 \\
Cyclohexanone & $\mathrm{Ga}(\mathrm{OTf})_{3}$ & 99 & 6 \\
\hline $\mathrm{Er}(\mathrm{OTf})_{3}$ & 82 & 10
\end{tabular}

${ }^{a}$ Ketone, $0.67 \mathrm{mmol} ; 60 \mathrm{wt} \%$ aq. $\mathrm{H}_{2} \mathrm{O}_{2}, 2.01 \mathrm{mmol}$; metal triflate, $10 \mathrm{~mol} \%$; toluene, $5 \mathrm{ml} ; 70{ }^{\circ} \mathrm{C}$, conversion and selectivity were determined using GC.

Next, the BV oxidation reactions of cyclic ketones of varied reactivity were carried out in the presence of two molar excess of $60 \mathrm{wt} \%$ aq. $\mathrm{H}_{2} \mathrm{O}_{2}$ and $\mathrm{Er}(\mathrm{OTf})_{3}$ or $\mathrm{Ga}(\mathrm{OTf})_{3}$. The following cyclic ketones were selected: cyclobutanone, 2-adamantanone, norcamphor, 2-methylcyclohexanone and cyclohexanone. Secondary groups in cyclic ketones are more prone to migrate than primary alkyl groups in BV oxidation. Therefore, norcamphor, 2-adamantanone and 2-methylcyclohexanone are more reactive then cyclohexanone which is moreover non-strained and hardly reactive in BV oxidation. Very reactive, strained cyclobutanone is readily oxidized with $\mathrm{H}_{2} \mathrm{O}_{2}$.

Results shown in Table 1 confirmed that metal triflates are highly active catalyst in BV oxidation of such cyclic ketones as 2methylcyclohexanone, cyclobutanone and 2-adamantanone.

However, our attempts to apply the developed reaction conditions for the synthesis of $\varepsilon$-caprolactone showed that the selectivity towards the lactone formation dropped significantly. In the reaction products the mixture of dimeric, trimeric or polymeric peroxides was detected. The quantitative analysis of this complex post reaction mixture was not possible, concerning the low thermal stability of peroxide species. The presence of dimeric peroxides has been already reported in the literature. The formation of dimeric peroxide was postulated by Baeyer and Villiger in their early works. ${ }^{1,13}$ However, numerous studies have shown that this peroxide under the influence of Lewis or Brønsted acids could not be converted into the appropriate lactone with high yields and

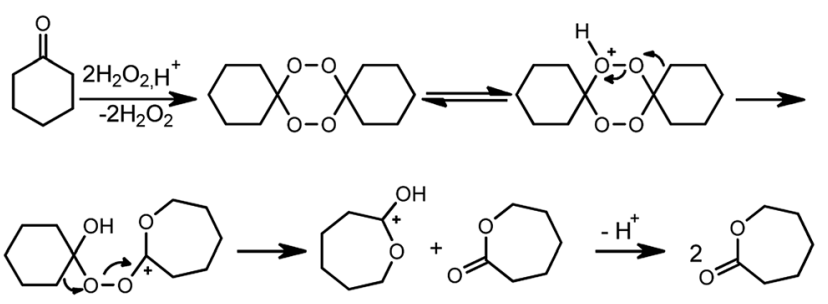

Fig. 4 Nonclassical mechanism of the BV oxidation with 50 wt $\%$ aq. $\mathrm{H}_{2} \mathrm{O}_{2}$ in fluorinated alcohols. ${ }^{17}$ 


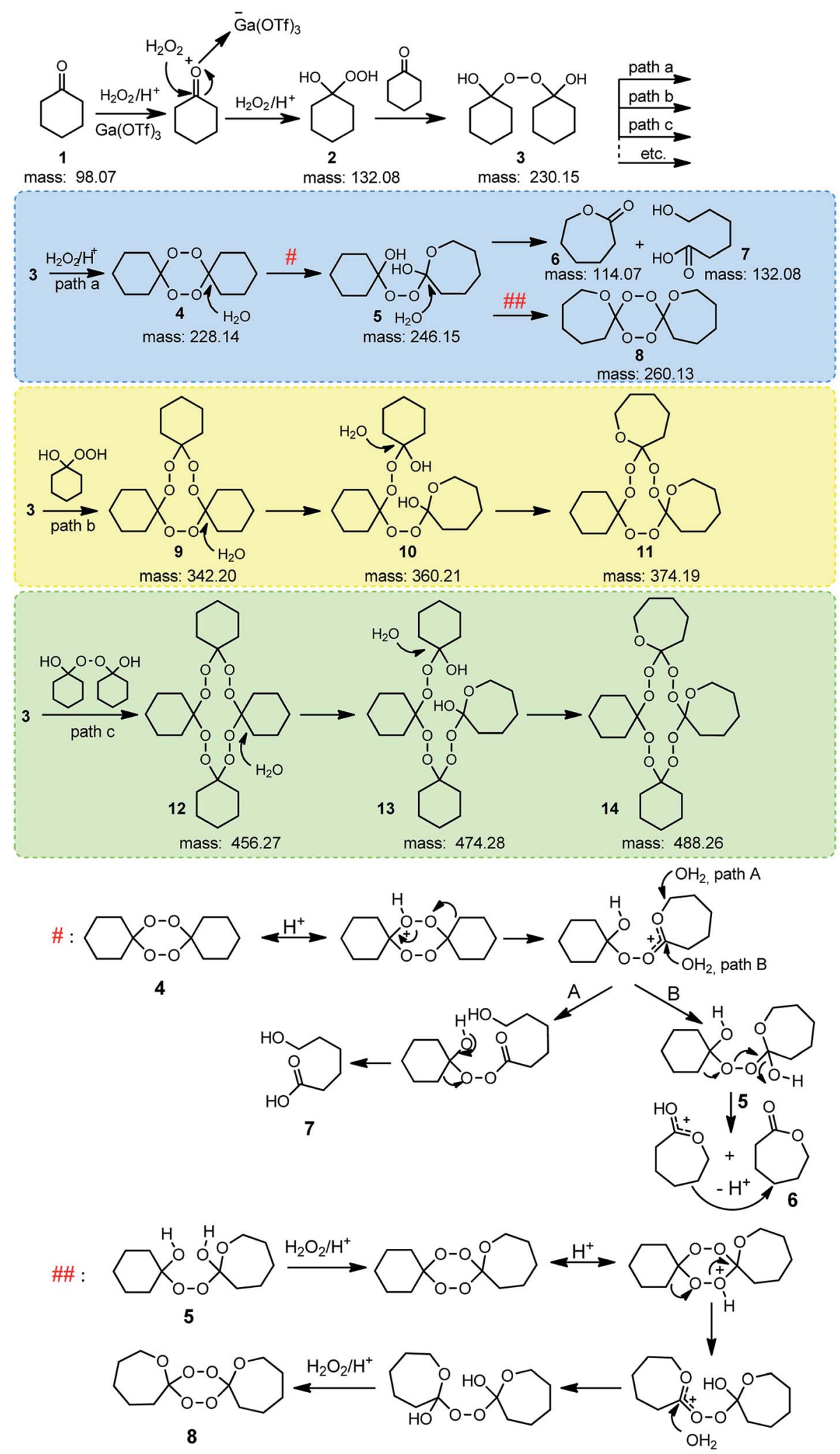

Fig. 5 Proposition of the BV oxidation mechanism of cyclohexanone with 60 wt\% aq. $\mathrm{H}_{2} \mathrm{O}_{2}$, in the presence of Ga(OTf) 3 . \# and \#\# according to. ${ }^{17}$

therefore was considered as a "dead end". conducted by Berkessel group showed that oxidation of cyclohexanone with hydrogen peroxide catalyzed by Brønsted acid, such as $p$-toluenesulfonic acid yielded $\varepsilon$-caprolactone only when carried out in the presence of 1,1,1,3,3,3-hexafluoro-2-propanol (HFIP) as a solvent ${ }^{16,17}$ (Fig. 4). Authors postulated that perfuorinated solvent 


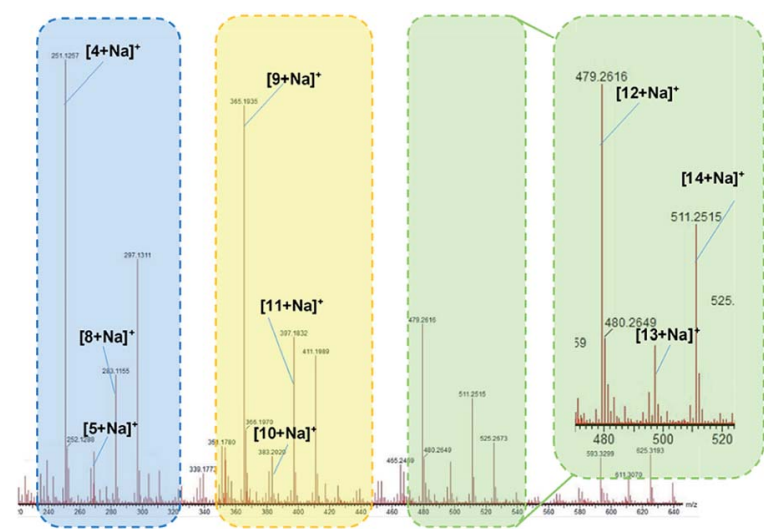

Fig. 6 MS spectrum of the post reaction mixture after the BV oxidation of cyclohexanone with 60 wt\% aq. $\mathrm{H}_{2} \mathrm{O}_{2}$, in the presence of $\mathrm{Ga}(\mathrm{OTf})_{3}$. The spectrum was recorded for the solution with Nal addition. facilitates the conversion of dimeric peroxide to lactone by creating strong hydrogen bonds to anions.

Few examples of the formation of trimeric peroxides are known in the literature. ${ }^{2}$ The synthesis of trimeric peroxides from 1,1'-dihydroperoxydicycloalkyl peroxides and ketones in the presences of $70 \%$ perchloric acids was described by Sanderson and Zeiler. ${ }^{18}$ Vennerstrom et al. observed the formation of trimeric peroxides - hexaoxonane derivatives - during ozonolysis of tetrahydro-4H-pyran-4-one. ${ }^{19}$ Hong and co-workers described the synthesis of hexaoxonane derivatives in the cyclocondensation of ketones with gem-dihydroperoxide catalysed by acid. ${ }^{20}$ The oxidation of acetone (linear ketone) with $30 \%$ hydrogen peroxide leading to formation of tetrameric acetone peroxide was also presented. ${ }^{21}$ However, to the best of our knowledge, the path of formation of trimeric peroxides and higher peroxides has not yet been presented. That encouraged us to gain an insight into the mechanism of the Baeyer-Villiger oxidation with hydrogen peroxide using metal triflates as

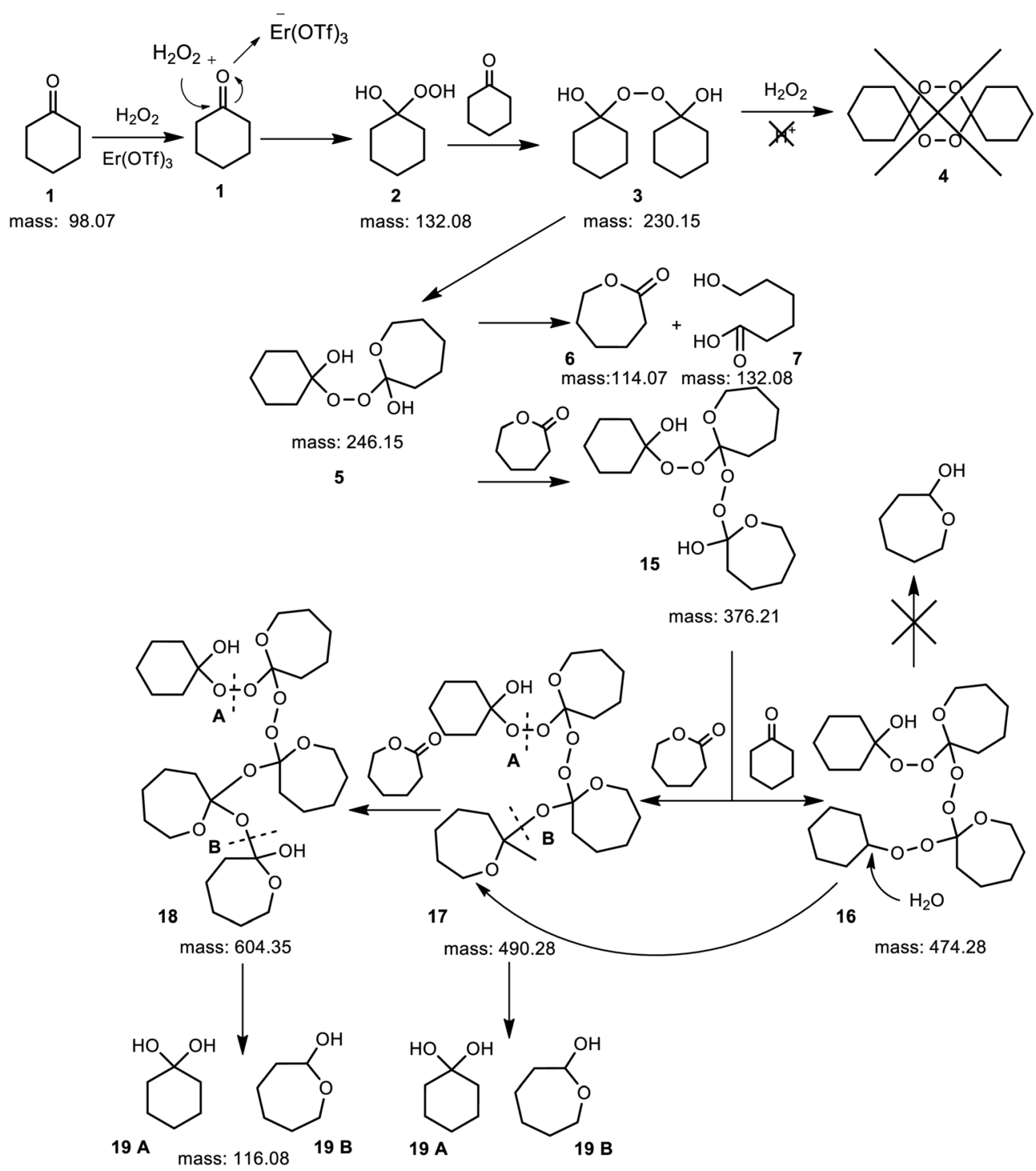

Fig. 7 Proposition of the BV oxidation mechanism of cyclohexanone with 60 wt\% aq. $\mathrm{H}_{2} \mathrm{O}_{2}$, in the presence of $\operatorname{Er}(\mathrm{OTf})_{3}$. 


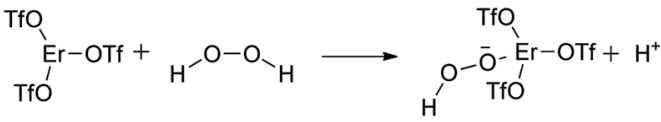

Fig. 8 Formation of labile proton in the reaction of hydrogen peroxide and $\operatorname{Er}(\mathrm{OTf})_{3}$.

catalysts and demonstrate if the triflate groups may play the similar role as a fluorinated solvent.

For gallium(III) triflate the conversion of cyclohexanone after 3 hours reached $99 \%$ while the selectivity towards $\varepsilon$-caprolactone was only $6 \%$ (Table 1 ). In order to clarify this phenomenon, we conducted high resolution MS analysis which showed that various peroxygen substances were present in the reaction mixture. Based on the outcome, we proposed a reaction mechanism in the presence of $\mathrm{Ga}(\mathrm{OTf})_{3}$ (Fig. 5). In the first stage, nucleophilic addition of hydrogen peroxide to the ketone occurs, resulting in the formation of perhydrate 2 . The perhydrate reacts with the cyclohexanone molecule to give dihydroxyperoxide 3. Then several paths are possible in which compound 3 undergoes further transformations. Spirobisperoxide $\mathbf{4}$ is formed in path a, which can be transformed according to the mechanism proposed by Berkessel. ${ }^{17}$ The transformations of $\mathbf{1 0}$ to $\mathbf{1 1}$ and of $\mathbf{1 3}$ to $\mathbf{1 4}$ proceed in exactly the same way as the transformation of 5 to 8 presented in Fig. 5, but for the sake of readability of the scheme only the final product is presented. The assumption that metal triflates can form hydrogen bonds like HFIP was used. However, gallium triflate was used in a catalytic amount, not as a solvent, so this is not the main path in which compound 3 is converted. In path $b$, compound 3 reacts with perhydrate to give trimeric peroxide 9 which then rearranges to 11. All intermediates, as well as transient states, were visible and identified on the MS spectrum (Fig. 6, see also in ESI, Fig. S1†).

A completely different mechanism was observed when reactions were conducted in the presence of erbium(III) triflate which shows high hydrolytic stability. In this case, triflic acid is not formed. Thus, the hydroxyl group of cyclohexanol of intermediate 3 was not protonated and cyclized to form the six membered cyclic peroxide 4. Instead of them the linear peroxides were presented in the reaction mixture. The proposed mechanism was not described yet in the literature (Fig. 7 and MS spectrum see in ESI, Fig. S2 †).

The experiments conducted in the same reaction conditions with 2-methylcyclohexanone, cyclobutanone and 2-adamantone showed that they can be converted to lactone in high yields (Table 1). In the presence of gallium(III) triflate the conversion of these ketones was higher than $97 \%$ and selectivity towards lactone reached 99\%, while for erbium(III) triflate the conversion and selectivity were higher than $94 \%$ and $80 \%$, respectively. MS analysis confirmed that the reaction proceeded in a similar way in the presence of both $\mathrm{Ga}(\mathrm{OTf})_{3}$ and $\operatorname{Er}(\mathrm{OTf})_{3}$ (see ESI, Fig. S3-S8†).

In both cases the formation of spirobisperoxide and lactone was observed according to the mechanism shown in Fig. 4 described in the literature. ${ }^{17}$ For the formation of a cyclic peroxide a labile proton is required. In case of $\operatorname{Er}(\mathrm{OTf})_{3}$ which is hydrolytically stable this proton could be created through the interaction between erbium(III) triflate and hydrogen peroxide (Fig. 8). Lower selectivity may also indicate a lower strength of Brønsted acid generated in situ in the reaction mixture.

In summary, based on the MS analysis the new mechanisms were evaluated concerning the formation of dimeric and trimeric peroxides when cyclohexanone was used as a substrate. On the other hand, when other ketones were used as the substrates the formation of spirobisperoxide was observed and the reactions proceeded with high conversion and selectivity. These studies develop the knowledge of the reactivity of cyclic ketones with hydrogen peroxide in the presence of metal triflates.

\section{Conflicts of interest}

The authors declare no conflict of interest.

\section{Notes and references}

1 M. Renz and B. Meunier, J. Org. Chem., 1999, 737.

2 G. J. Brink, I. W. C. E. Arends and R. A. Sheldon, Chem. Rev., 2004, 104, 4105.

3 C. Jiménez-Sanchidrián and J. R. Ruiz, Tetrahedron, 2008, 64, 2011.

4 R. A. Michelin, P. Sgarbossa, A. Scarso and G. Strukul, Coord. Chem. Rev., 2010, 254, 646.

5 A. Corma, L. T. Nemeth, M. Renz and S. Valencia, Nature, 2001, 412, 423.

6 S. Kobayashi and K. Manabe, Pure Appl. Chem., 2000, 72, 1373.

7 S. Kobayashi, M. Sugiura, H. Kitagawa and W. W. L. Lam, Chem. Rev., 2002, 102, 2227.

8 A. Berkessel, E. Ashkenazi and M. R. M. Andreae, Appl. Catal., A, 2003, 254, 27.

9 M. Markiton, A. Ciemięga, K. Maresz, A. Szelwicka, J. MrowiecBiałoń and A. Chrobok, New J. Chem., 2018, 42, 13602.

10 M. Markiton, A. Szelwicka, S. Boncel, S. Jurczyk and A. Chrobok, Appl. Catal., A, 2018, 556, 81.

11 W. v. E. Doering and E. J. Dorfman, J. Am. Chem. Soc., 1953, 75, 5595.

12 P. E. Blatz and D. L. J. Pipert, J. Am. Chem. Soc., 1968, 90, 1296.

13 A. Baeyer and V. Villiger, Ber. Dtsch. Chem. Ges., 1900, 33, 858.

14 L. Ruzicka and M. Stoll, Helv. Chim. Acta, 1928, 11, 1159.

15 W. Dilthey, M. Inckel and H. Stephan, J. Prakt. Chem., 1940, 154, 219.

16 A. Berkessel and M. R. M. Andreae, Tetrahedron Lett., 2001, 42, 2293.

17 A. Berkessel, M. R. M. Andreae, H. Schmickler and J. Lex, Angew. Chem., Int. Ed., 2002, 41, 4481.

18 J. R. Sanderson and A. G. Zeiler, Synthesis, 1975, 6, 388.

19 Y. Dong and J. L. Vennerstrom, J. Org. Chem., 1998, 63, 8582.

20 A. B. Rode, K. Chung, Y. W. Kim and I. S. Hong, Energy Fuels, 2010, 24, 1636.

21 H. Jiang, G. Chu, H. Gong and Q. Qiao, J. Chem. Res., 1980, 2 , 34. 